\title{
Advocacia epistemológica desempoderada: a ciência da comunicação segundo Luiz Claudio Martino
}

Francisco Rüdiger

\section{Resumo}

Luiz Claudio Martino desenvolveu importante contribuição à formação da área que, entre nós, assumiu o nome de epistemologia da comunicação. 0 artigo resume a proposta e tece comentário crítico a seu respeito. A conclusão da análise é a de que, a despeito de sua seriedade e alto nível acadêmico, a argumentação por ele apresentada não sustenta adequadamente sua defesa da autonomia científica da área acadêmica de comunicação.

\section{Palavras-Chave}

Luiz Claudio Martino. Epistemologia da Comunicação. Crítica do Pensamento Comunicacional.

\section{Francisco Rüdiger}

Doutor em Ciências Sociais pela Universidade de São Paulo - USP, São Paulo. Professor Titular da Faculdade de Comunicação da Pontifícia Universidade Católica do Rio Grande do Sul (Porto Alegre, Rio Grande do Sul, Brasil) e da Universidade Federal do Rio Grande do Sul (Porto Alegre, Rio Grande do Sul, Brasil). E-mail: frudiger33@gmail.com
Ponto de partida para a emergência de uma nova especialidade acadêmica, em que passaria a se engajar parte dos teóricos brasileiros da área, foi o I Seminário Nacional de Epistemologia da Comunicação, realizado na Universidade de São Paulo (USP) pela Compós em 2002 (cf. LOPES, 2003). Durante seus anos de ascensão, predominara na área 0 entendimento, reconhecidamente muito frouxo, de que, considerados em seus fundamentos científicos, os estudos ali feitos seriam inter ou multidisciplinares. Advinda a expansão dos Programas de Pós-Graduação no final dos anos 1990, todavia, surgiram vozes para quem esse discurso teria se tornado anacrônico. Chegara a hora de justificar o campo acadêmico com a explicitação da autonomia epistemológica da disciplina que, de fato ou potencialmente, estaria nele contida.

Personagem de proa deste movimento foi, sem dúvida, Luiz Claudio Martino, não só por levantar a bandeira, mas, a despeito do passar dos anos, por persistir no esforço. Seus principais trabalhos acabam de ser reunidos em "Escritos sobre 
Epistemologia da Comunicação" (MARTINO, 2017). Segundo o autor, os estudos da área de comunicação vivem sob o risco de entrar em colapso epistemológico e, assim, perder sua legitimidade acadêmica, pelo fato de não terem definido bem sua identidade como saber. 0 "saber comunicacional", isto é: 0 oriundo da área, impôsse pela evidência, sem esclarecer suas bases científicas, mas isso estaria agora impedindo seu desenvolvendo, se não ameaçando levá-lo ao descrédito intelectual e acadêmico.

A fim de evitá-lo, haveria apenas uma saída: examinar seus fundamentos epistemológicos e desenvolver seu embasamento teórico como ciência. Amadurecera o momento de "analisar suas insuficiências epistemológicas", para promover 0 seu desenvolvimento racional e coordenado como disciplina (MARTINO, 2017, p. 178-180). Sair do conformismo e repensar os termos em que se baseia sua atividade: eis o que, doravante, exigir-se-ia dos estudiosos desse setor acadêmico. 0s critérios que legitimam suas práticas sedimentaram-se sem a devida reflexão, supondo truísmos infantis.

A postulação ontológica de que a comunicação é um "princípio essencial à atividade humana" não basta mais para justificá-la no plano epistemológico (MARTINO, 2004, p. 12). À área exige-se a apresentação de suas credenciais como seção autônoma do conhecimento científico, e isso segue o raciocínio do colega - se estabeleceria com a demarcação de seu objeto de estudo "de tal forma que ele não coincida com o objeto de nenhuma outra [disciplina"] (MARTINO, 2001, p. 64).
Queremos no que segue relatar criticamente esse projeto, conduzido com a maior seriedade, esperando abrir debate mais amplo sobre questões de fundo que deveriam interessar a, virtualmente, todos os acadêmicos com responsabilidade científica na área em questão nestas páginas.

\section{A causa}

Durante décadas, dissemos, pretendeu-se que os conhecimentos comunicacionais eram interdisciplinares; eles não teriam autonomia científica (POLISTCHUK, RAMOS TRINTA, 2003; LOPES, 1990; MOREIRA, 1979; SÁ, 1973).

Mérito de Martino é o de reabrir 0 debate a respeito - debate este que se projetou para além do marco anteriormente tentado. Houve momento em que, reclamando os poderes da cibernética, chegou-se a cogitar a respeito de uma ciência geral da comunicação. Agora, convém que se evite tal ambição, defende 0 autor, uma vez que a área fará bem em restringir seus interesses epistêmicos ao que cabe no domínio das humanidades.

Questionamento central posto nos seus escritos é feito ao ceticismo com que é vista a sua autonomia disciplinar. Argumenta-se que, à luz de reflexão epistemológica, as reticências quanto a isso se resumiriam a preconceito intelectual. Ao menos embrionariamente, haveria uma ciência disciplinar autônoma no campo da comunicação. Será, porém, que a tese se sustenta? 
Findo 0 século 20, parecia que a área havia conquistado posição administrativamente bastante firme no cenário acadêmico brasileiro. Repentinamente, contudo, o cenário mudou, devido a alterações legais determinadas pelo Conselho Federal de Educação. Hoje, os diplomas com referência ao termo encontram-se em vias de desaparecimento (permanece só para os cursos de publicidade). A área, talvez seu pessoal ainda não tenha percebido bem, resiste essencialmente apenas no âmbito da pós-graduação.

Será, porém, que, mesmo os estudos por ventura científicos feitos neste contexto, pouco importa 0 gênero, só por isso adquiriram autonomia científica perante as demais áreas do conhecimento? Martino aposta que sim, ao condenar o ceticismo que, acabando por pregar 0 reconhecimento do cunho importado - poli ou interdisciplinar - dos métodos e conceitos nele articulados, obstaculizaria seu pleno desenvolvimento como disciplina autônoma. Partindo daí, vai-se, contudo, bem além, porque o desejo central de seu projeto é, também, identificar 0 objeto da ciência especializada e distinta que ele pretende que haja na área acadêmica de comunicação.

Ao discurso da interdisciplinaridade que ronda a área não cabe apresentar menor crítica da que deveríamos dirigir ao ceticismo em relação à cientificidade dos estudos comunicacionais. Sentido daquele primeiro é a sublimação do intelectualismo mercadológico dominante no sistema midiático (MARTINO, 2017, p. 114-116). Interdisciplinaridade como chave de entendimento epistemológico da área de comunicação é um reflexo ou efeito dos modismos daquele intelectualismo na atividade acadêmica. Quer 0 autor, por isso, que a área também se livre desta categoria: interdisciplinaridade, se é mesmo para desenvolver sua autonomia científica.

Curiosamente, de acordo com ele, o caminho para tanto, todavia, não passa pela prática de pesquisa concreta e por seu exame crítico por parte da comunidade acadêmica nela engajada. A arma designada e a ser empregada é, antes, a reflexão epistemológica genérica e em abstrato. Credenciando o termo, Martino apresenta-se ao leitor como "comunicólogo" (p. 37). Isto é, o sujeito capaz de articular em pensamento as práticas e técnicas da comunicação social. Seria alguém capaz de desenvolver suas conexões com a teoria e entendê-las como práxis, para usar os termos de Mendes de Barros (2004, p. 11; cf. MARTINO, 2007).

No entanto, acontece que é como filósofo da ciência que ele, Martino, de fato, se comporta, visto que almeja expor os fundamentos epistemológicos da disciplina que supostamente daria conta do assunto. Sua obra pouco ou nada revela sobre a atividade concreta que aquela última - a comunicologia - já teria revelado, tanto quanto sobre os trabalhos efetivamente feitos até agora na área. A eventualidade de, nesta última, as teorias do jornalismo ou da propaganda, para 
não falar de outras tantas oriundas das ciências sociais, serem, na pesquisa, muito mais relevantes do que as referentes à comunicação propriamente dita (cf. RÜDIGER, 2011) não é cogitada.

Martino articula seus relatos essencialmente com base na filosofia (geral) da ciência: não há sinal de esforço em tentar pensar eventual originalidade presente em fenômeno que é a constituição de um campo acadêmico como 0 da comunicação (RÜDIGER, 2007). Fora raras menções nominais (importadas de outras áreas) de um ou outro relato, também não se vê em sua obra nenhuma análise da pesquisa de fato feita e utilizada por sua respectiva comunidade.

Quase toda a literatura oriunda ou a respeito da área de comunicação, empregada no texto, tem cunho puramente teórico. Apesar de vasto e gabaritado, o repertório de que se vale 0 autor passa ao largo do que se origina da investigação propriamente dita (isto é, histórica, empírica ou experimental).

Dando como certo que há ou pode haver uma comunicologia, volta e meia Martino afirma que essa é tal porque pode ter suas próprias teorias (MARTINO, 2017, p. 227) - sem que mostre nenhuma: todas as citadas em sua obra de síntese pertencem a outros ramos do saber. Alheio a um exame da pesquisa que, de fato, é feita na área (no campo acadêmico), argumenta o autor que, pela reserva de mercado temática (a problemática da comunicação moderna, vide p. 127), é possível dar àquela primeira, à área, um disciplinamento científico, identificar a ciência que, de direito, pertenceria aos cursos de comunicação.

Desconhecendo a ressalva de que a cientificidade não é questão "que possa ser respondida através de um acordo sobre definições" (KUHN, [1962] 1975, p. 202), ele parte da premissa historiográfica de que o campo encontra-se teoricamente fragmentado, submetido a abordagens de estudo que se originam de outras disciplinas. 0 pior de tudo seria, porém, que o setor está acomodado com uma concepção a respeito de sua própria natureza e com fundamentos que, se não simplesmente errônea e contraproducente, seria enganosa. Os porta-vozes da área tornaram-se prisioneiros de uma reflexão epistemológica extremamente frágil, que os leva a desperdiçar seu capital intelectual "mobilizando a filosofia para opô-la à ciência" (MARTINO, 2017, p. 276-278).

Condenando o entendimento interdisciplinar da área acadêmica de comunicação pelo fato de levar suas teorias "a coincidir com 0 conjunto das ciências do homem", Martino dá voz ao desejo, abrigado em alguns de seus colegas, de conferir aos estudos feitos nela a autonomia científica que esses estudos adquiriram administrativamente com o surgimento dos cursos e faculdades. "A abertura a todo e qualquer problema que resulte em algum produto comunicacional" existente hoje não deveria continuar, se é para dispormos de um verdadeiro "conhecimento comunicacional" (MARTINO, 2004, p. 3). 
As postulações no sentido da

interdisciplinaridade e/ou o ceticismo em relação à identidade disciplinar que dominam 0 campo não resistiriam à análise epistemológica.

A afirmativa de que o estado do campo pode servir de base para definir 0 estatuto de seu saber é falaciosa. Os problemas epistemológicos não podem ser resolvidos com métodos históricos ou sociológicos. A "comprovação da falta de identidade disciplinar pelos dados históricos" feita por alguns arautos do campo esquece que estes dados são "organizados pelo pressuposto que querem comprovar". A pesquisa documental raramente retira deles "o que foi ali implicitamente colocado" (MARTINO, 2004, p. 4).

Martino não considera que se, por um lado, a identidade do campo não pode, de direito, ser fruto de uma definição arbitrária, de outro a trajetória histórica e situação intelectual, sempre passíveis de revisão, nele, contudo, influenciam. Vale notar, com efeito, que a identidade, uma categoria originária da lógica, forma-se concretamente na práxis, de modo, portanto, variável, plural e contraditório (FEENBERG, 2014; KLIMSTER, 1979; FAY, 1987; HABERMAS, 1987, p. 216-272). Significa que a história também serve de argumento, ao se analisar o perfil inerente à área - com 0 que, no entanto, discorda Martino. Para ele, o estado do campo e as declarações de seus porta-vozes não podem mais servir de base para definir seu estatuto epistemológico.
As premissas que, até agora, guiaram o primeiro foram aceitas sem a devida análise, carregando enorme passivo epistemológico, argumenta. 0s pesquisadores precisam, pois, se comprometer com um trabalho de sistematização disciplinar mais consequente (MARTINO, 2004, p. 9). A proliferação de teorias é algo para ser controlado ou reduzido. A delimitação do próprio campo deve passar a ser o foco dos teóricos que laboram no campo acadêmico da comunicação. 0 edifício que a área construiu não tem bons fundamentos e, por isso, pode desabar sobre as iniciativas de seus praticantes.

Agora seria hora de a área olhar para frente, começando por distinguir entre "teorias sobre 0 fenômeno da comunicação" e "teorias da [área de] comunicação", visto que, "por detrás de hábitos linguísticos, se esconde uma grande e inaceitável confusão entre objeto de análise (o fenômeno comunicacional) e análise do objeto (o tipo de saber a que se recorre)" (MARTINO, 2017, p 175) .

As primeiras teorias tratam da comunicação desde o ponto de vista de saberes que não seriam comunicacionais, ao originarem-se das demais ciências humanas. As segundas seriam, ao contrário, estas que desenvolveriam um saber intrínseco ao campo acadêmico da comunicação. A área só se desenvolverá, crê 0 autor, se se comprometer com estas últimas, visto que não há outro modo de constituir uma problemática comunicacional distinta e autônoma em relação às abordagens alienígenas (MARTINO, 2017, p. 176). 
Martino observa bem que a epistemologia constitui uma disciplina filosófica e designa o estudo da ciência. Segue neste registro, postulando que lhe cabe analisar se e como esta última, na sua variedade, maneja as premissas que norteiam a atividade de pesquisa. 0 embaraço começa quando começa a defender que a epistemologia "é parte integrante e inalienável de cada disciplina científica" (MARTINO, 2017, p. 8-11).

Afinal, o fato de a epistemologia poder ser acoplada à atividade científica não significa que ela "passe a ser ciência", já que, como 0 autor mesmo diz, em sendo "estudo da ciência", ela é sempre metalinguagem. A epistemologia extrapola sua jurisdição, movimenta-se do plano analítico e reflexivo para o teórico e normativo, ao pretender dar conta do objeto de estudo das ciências, admitindo-se que esse objeto se constrói na práxis da investigaçãa ${ }^{1}$.

Associando-se a Immacolata Lopes (1990, p.

105-107), ele afirma que "todo trabalho científico comporta uma dimensão epistemológica"
(MARTINO, 2003, p. 82). A proposição não

está errada, concordamos, se a entendermos a partir do ponto de vista de quem o aborda reflexivamente. 0 pesquisador mesmo pode, porém, desconhecê-la, sem que isso importe necessariamente em prejuízo, porque, como tal, pesquisador, está engajado em outro tipo de tarefa: a pesquisa e a análise empírica, formal ou histórica de seu tema de investigação².

Martino expressa em seus escritos a nostalgia destes que, apresentando-se em campos acadêmicos surgidos mais tarde, ainda conservam como referência o tempo em que, referindo-se a uma filosofia mais ou menos consensual, as ciências formavam um sistema, separavam-se hierarquicamente em disciplinas e se legitimavam pela formação proporcionada por um currículo mínimo talhado por uma doutrina éticoprofissional e um discurso epistemológico de cunho doutrinário.

Visivelmente lhe descontenta o fato de as faculdades de comunicação serem uma espécie

Lucrécia Ferrara fornece ilustração deste problema em um dos vários textos, notadamente confusos, com que intervém no campo da epistemologia da comunicação, ao afirmar que "a epistemologia da comunicação exaure-se em insuficiente esforço para definir o único elemento que poderia identificá-la: trata-se do objeto científico da comunicação". Para ela, tente 0 leitor decifrar a passagem: "Essa definição envolve dificuldade, porque enfrenta a relação propriamente cognitiva que ocorre entre um sujeito investigador, que não se coloca como célula irrefutável de um saber hegemônico, e um objeto que não está inerte, mas vivo nas constantes modelizações que the são sugeridas pelos contatos sociais, culturais, econômicos e tecnológicos que o envolvem. Imerso naquelas constantes, mas vivo para conformar-se sem modelar-se por pressupostos e manipulações, esse objeto se mostra ontologicamente indeterminado, mas surge epistemológica e cognitivamente presente nas modelizações que se liquefazem na própria ação que traduz a comunicação no comunicar, a ontologia na epistemologia, o campo científico na arquitetura de um objeto" (FERRARA, 2012, p. 33-34).

A reflexividade epistemológica pode ser recomendada a uma comunidade científica, mas, salvo prova documental, não é necessária à boa condução de uma pesquisa. A argumentação a respeito deste último aspecto, na ciência, só se revela apropriada com base na análise de estudos de caso e relatos concretos. 0 resto pode ter interesse filosófico, mas se esgota em imposição de doutrina, ao virar cobrança abstrata (cf. LOPES, 2010). 
de vanguarda desta época em que a preocupação em responder às demandas do mercado de trabalho, a proliferação de especialidades cada vez mais pontuais, a sanha burocrática, 0 trabalho tarefeiro, 0 atendimento de metas, 0 foco na instrumentação, o acesso em massa e a banalização do ensino tornaram, na maior parte das áreas, patética a invocação da velha figura da ciência (LYOTARD, [1979] 1986, p. 69-123; RÜDIGER, 2007).

Em síntese, deseja separar os estudos feitos na área acadêmica de comunicação do campo muito mais vasto representado pelos estudos sobre comunicação (cf. MERRIN, 2014, p. 107115). "0 comunicólogo deve explicar a realidade humana a partir dos fenômenos comunicacionais" (MARTINO, 2007, p. 16), escreve, e isso, para ele, significa explicar esta realidade, a comunicacional, tomando as instituições que nela se especializaram, os meios de comunicação, como fator privilegiado para teorização e estudos.

\section{Ajuizamento}

Em nosso ver, o problema de fundo com todas essas ideias está em supor que formulações abstratas como a realizada bastem para fundar uma nova disciplina científica. Decerto o autor tem razão em dizer que a comunicação, como processo social, não é um objeto empírico (MARTINO, 2007, p. 27); que a área portadora do nome surgida no meio acadêmico pode se especializar no estudo de suas mediações tecnoculturais: a mídia. Mas isso não significa que, para se ocupar desses fenômenos, 0 termo "mídia" tenha de ser construído teoricamente, muito menos que essa construção, em havendo, deva ser obra de uma disciplina separada das demais humanidades (a "Comunicologia").

Os estudiosos dos fenômenos de mídia não precisam, necessariamente, trabalhar na área acadêmica de comunicação. 0 fato de as teorias com que os profissionais desta última operarem não lhes serem nativas não exige 0 bovarismo acadêmico. 0 desejo de instaurar um "saber autônomo" não deveria se deixar aprisionar pelo fetichismo das repartições administrativas.

Quais são os motivos para sua angústia epistemológica com a situação da área, o autor aqui considerado não deixa muito claro, embora 0 seja 0 fato de ele se sujeitar acriticamente ao positivismo, à crença na ciência pela ciência. Entre as provas disso, está sua concepção de epistemologia, a convicção de que esta tem por missão dar aos praticantes de um saber a direção na qual deve ele progredir (cf. RAYMOND, 1978, p. 9-55).

Martino pretende que a área de comunicação tenha suas próprias teorias para, assim, fundamentar epistemologicamente a autonomia de um novo ramo da atividade científica. Sugere que tais teorias, embora ainda não existam, podem ser criadas e serem distinguidas das que circulam nas ciências humanas. 0 problema todo é que não 
nos dá motivo para pensar que isso tenha algum fundamento outro que não seu voluntarismo epistemológico.

Em sua linha de raciocínio, os relatos de pesquisa objetivamente existentes em artigos, livros e teses não podem, por princípio, servir de prova alguma para sua epistemologia da comunicação. Ignorando o que assegura a autonomia da atividade científica, 0 autor confere à epistemologia um aspecto construtivo e doutrinário, que se projeta abstrata e dogmaticamente sobre as tarefas daquela primeira. A epistemologia assume um caráter normativo e fundacional, visto ele lhe atribuir a capacidade de, concretamente, regrar o próprio objeto daquela atividade. 0 resultado é uma confusão entre as tarefas de cada uma dessas instâncias: a científica e a epistemológica.

Preconiza Martino que pecado da área é o fato de ela não dispor da reflexão epistemológica que procederia à sua sistematização, no sentido de fazer convergir teses e proposições, de impor uma disciplina na conduta e nos trabalhos de seus integrantes. Questão que urge colocar, porém, é: por que precisariam fazê-lo? Que alguém 0 tente, não está, de modo nenhum, proibido: mas há necessidade? 0 autor procede como se a sistematização, no sentido da confecção de uma "teoria geral" ou da explicitação de um "princípio unitário", a elaboração de um cânone epistemológico sobre o que fazer e como se portar fosse não apenas desejável e possível, mas indispensável à sobrevivência acadêmica e intelectual dos estudos de mídia (RÜDIGER, 2014).

Ocorre que isso não se sustenta: 0 campo acadêmico da comunicação surgiu e vem prosperando à revelia dessa exigência, que pode interessar e ser esperada normativamente pela filosofia da ciência mais clássica, mas não é necessária para ajuizar os resultados da atividade de pesquisa e, mesmo, manter uma comunidade acadêmica. Seguir por aí nos conduz acriticamente ao positivismo normativo, à pregação da ideia de que, embalada por seu entendimento como doutrina, cabe à epistemologia a exclusividade de definir o objeto de estudo dos pesquisadores integrados ao campo.

Tarefa da epistemologia, segundo Martino, seria estabelecer o estatuto do "conhecimento comunicacional" enquanto tal, o que não estaria errado se, assumindo um viés empírico e analític $0^{3}$, seu interessado focasse no trabalho de pesquisa e, assim, alcançasse conclusões gnosiológicas sobre os estudos efetivamente conduzidos no campo. A questão é que, desprezando essas realidades, em favor da condução de estudos sobre as teorias nele presentes, arrisca 0 autor a tese de que 
o discurso epistemológico, por si só, pode instaurar esse estatuto.

Destarte, seus textos bastam-se no falar sobre 0 campo acadêmico, evitando a pesquisa de fato nele realizada, para chegar à conclusão de que as teorias lá presentes, até o momento, não ajudam a lhe dar consistência científica, "não podem nem pretendem oferecer a fundamentação necessária para a sistematização da área [no plano epistemológico]" (MARTINO, 2017, p. 177).

0 autor observa bem que, via de regra, a comunicação, na literatura especializada, não aparece como termo que explica, para defender que só com isso se poderia fundar uma "pesquisa empírica" singular e autônoma. Porém, em vez de, enquanto epistemólogo, partir do exame da pesquisa efetivamente realizada, a fim de avaliar e mostrar como e se 0 que diz foi feito, pensa ele poder estabelecer tal coisa definindo genericamente um objeto de conhecimento aos colegas comunicólogos.

Nisso, segue ele a trilha de José Luiz Braga, para quem "a constituição da Comunicação como disciplina" consiste, essencialmente, em um "desenvolvimento teórico", já que "o conjunto de descobertas empíricas sobre fenômenos" não bastaria para "caracterizar uma área de conhecimento". Aparentemente, também para ele, vale a ideia segundo a qual a "elaboração teórica" em que constituiria epistemologicamente uma "disciplina" se desenvolve com a ultrapassagem dos estudos de caso em favor de "níveis abstratos de reflexão" (BRAGA, 2010, p. 403).

0 juízo, soando convincente, é sedutor - mas, pode-se perguntar aos dois autores: onde estão, se não as provas, pelos menos os argumentos? A pretensão é algo mais do que uma tese essencialmente abstrata e desejante? Braga (2010) e outros (MATTOS et al., 2018, p. 27-332) supõem que, para lastrear o que almejam, basta um levantamento dos temas e das intenções dos trabalhos feitos na área. A elaboração de uma tipologia, todavia, tem pouca serventia no que estamos tratando, se não se observarem cuidados anteriores e mais importantes. A tarefa precisa, necessariamente, ser precedida de um exame analítico dos procedimentos efetivamente desenvolvidos em cada documento. A separação dos relatos de investigação científica dos exercícios ensaísticos e reflexões teóricas se afigura, por exemplo, fundamental, nesse sentido.

Martino não somente passa o ponto por alto, mas também, em seu sobrevoo, lança-nos em proposição teórica muito mais elementar. Sinal do pouco alcance de seu projeto epistemológico está na forma trivial com que, assumindo o papel de porta-voz da área, em sentido administrativo, conclui ele, após tortuosas reflexões, que 0 objeto da sua ciência seria constituído pelos meios de comunicação modernos: rádio, televisão e internet, por exemplo, mais os discursos e representações que agenciam; em resumo e sofisticando: o que se tem chamado de processo de midiatização da sociedade. 
Análoga formalmente ao projeto de Braga

(RÜDIGER, 2017), verifica-se na sua empresa 0 desejo de, pela sintonia fina, revelar um objeto de conhecimento capaz de distinguir o saber que seria comunicacional de todos os demais (MARTINO, 2017, p. 12-13). Em última análise, contudo, não se chega além do que outros, com mais refinamento e análise, identificaram com 0 termo midiatizaçã $0^{4} .0$ problema, observe-se, não se resume na trivialidade hermenêutica desta teoria: estende-se ao fato de que endossá-la não seria da conta da epistemologia ${ }^{5}$.

À epistemologia sem dúvida toca explicitar e discutir a forma como os pesquisadores eventualmente entendem os meios de comunicação. A proposição, no entanto, não implica que ela tenha de tomar para si a tarefa de propor uma abordagem "comunicacional" dos fenômenos associados aos meios de comunicação.
A cientificidade não se constrói com recortes factuais ou discurso doutrinário, mas mediante a prática da pesquisa calcada em experiências determinadas, analisadas metodicamente.

\section{Corolários}

Martino comete a proeza de, na sua obra de síntese, não examinar sequer um relato de pesquisa ${ }^{6}$, limitando-se a postular que a Comunicologia, entendida por ele como estudo científico da mídia, institui-se disciplinarmente na medida em que fornece "explicações comunicacionais de processos comunicacionais" (MARTINO, 2017, p. 279300). De acordo com seu ver, lembremos, as ciências sociais estudam a humanidade em suas várias formas de convívio e relacionamento. A Comunicologia seria uma de suas disciplinas, na medida em que lhe caberia

Apresenta-se como tal, nos últimos anos, fenomenologia cujas origens, possuidoras de um acento crítico e de uma complexidade histórica e dialética que agora se perderam, remontam a meados dos 1940. Adorno e Horkheimer escreveram que, em nossa era: "0 mundo inteiro é forçado a passar pelo filtro da indústria cultural” ([1947] 1985, p. 118). A trivialidade escolástica em que 0 conceito, convertido em "matriz teórica", tende a cair atualmente pode ser vista, por exemplo, em Lundby (2014), Merrin (2014) e Hjarvard (2014) (cf. RÜDIGER, 2015).

Vera França situa-se na perspectiva de Braga e Martino, por também postular a propriedade epistemológica de uma "problemática comunicacional" no saber contemporâneo. De acordo com ela, "a experiência se torna objeto 'comunicacional' ao começarmos a estudá-la enquanto 'comunicacional'” (FRANÇA, 2016, p. 157). Significa que o fundamental é, pois, definir este aspecto (0 "comunicacional") do conhecimento humano: sua conceituação é essencial para instituir a ciência, visto só assim "se puder distinguir e aprender, na empiria, algo passível de ser chamado e entendido [cientificamente] como comunicação". Quando à definição que nos é apresentada (FRANÇA; SIMÕES, 2017), surgem, porém, motivos para novo desânimo. Afirmam a autora e sua colega, que, vislumbrada como viés analítico, refere-se ao "comunicacional", à "circulação de sentido entre duas ou mais pessoas", à "atividade de troca simbólica através da produção de material discursivo em certos contextos". Deixando a exploração do que há de problemático na ideia, lançamos aqui uma única pergunta sinalizadora: por que, em vez de viés analítico intrínseco à ciência comunicacional, não se está, com isso, diante de uma formulação abstrata e genérica de o que, por exemplo, estuda a antropologia?

Salvo engano, o repertório bibliográfico não refere mais de quatro (Wernerck Sodré, Elizabeth Eisenstein, Edwin Emery, Paul Lazarsfeld). "Panorama da pesquisa empírica em comunicação" (MARTINO, 2010) logra mencionar casos concretos (Lazersfeld, Herzog). Todavia não vai além da observação genérica visando à ilustração de doutrina. 
esclarecer o fenômeno humano pelo ângulo dos processos midiáticos (MARTINO, 2017, p. 299-300).

Destarte, sustenta 0 autor que a comunicação pode, como área, ser dona de sua própria concepção epistemológica, na medida em que um objeto de conhecimento lhe venha a ser específico, que é preciso dar a este uma formulação precisa, se é mesmo para termos uma ciência propriamente comunicacional. Sentimento de frustração é o que nos resta, contudo, após sabermos que esse objeto não seria outro, porém, que não o processamento midiático (simultaneamente simbólico e tecnológico) das várias práticas sociais (MARTINO, 2017, p. 71).

Afinal, afigura-se claro que, exceto pela conveniência da divisão do trabalho, nada impede que, por exemplo, a história ou a antropologia encarreguem-se desse estudo. Por que essas e outras disciplinas estariam impedidas de estudar os fenômenos de mídia? Por que elas não seriam, em parte, claro, ciências pertinentes à comunicação (no sentido de setor acadêmico-administrativo)? Por que, sujeitas a um estudo epistemológico, as pesquisas delas provenientes não poderiam se revelar de maior alcance em termos de saber, do que as realizadas na área de comunicação? ${ }^{8}$

Martino tem consciência de que as ciências humanas podem dar conta dos fenômenos conexos aos meios de comunicação. A economia política e os estudos culturais, apenas para dar exemplo, têm condições de fazê-lo; não estão proibidas de, ilustremos, estudar a televisão. A publicidade e o noticiário não são, em si mesmos, um fato comunicacional, porque é possível vê-los como meios de ação empresarial, ainda argumentaria.

0 epistemólogo que ele encarna, no entanto, crê que, ao se identificar o referido fator ("comunicacional") com a capacidade de os meios técnicos agenciarem socialmente determinados simbolismos, seria possível fundamentar uma autonomia científica para a área de comunicação. A pergunta que fica em aberto diz respeito aos problemas, teorias, métodos e técnicas de pesquisa que distinguiriam seus trabalhos dos disponíveis nas disciplinas estabelecidas.

Qual é o indicador que nos permite mencionar 0 "comunicacional", sem cair na trivialidade do

Indicação disso seria, por exemplo, "a influência da publicidade sobre o mercado, um vazamento de informações com graves consequências políticas, ou uma notícia que altera o comportamento dos investidores etc." (MARTINO, 2013, p. 209).

Midiatização, observe-se, não é um conceito "comunicacional”, quer no sentido epistemológico: não é necessário para sustentar uma teoria da comunicação humana; quer no sentido acadêmico: as especialidades humanísticas não estão proibidas de empregá-Io - na verdade, encontram-se em sua origem e, hoje, seguem Ihe dando a fundamentação (RÜDIGER, 2015).

De acordo com nosso entendimento e com o que supomos ser o pensamento do autor discutido neste artigo, seria, no caso, mais adequado empregar o termo "midiático". 
esquema emissor-mensagem-receptor? Falar em "atualidade midiática" tem relevância metodológica objetiva na prática de investigação? Há nisso tudo algo mais que uma referência ingênua e protocolar ao que envolve ou tem a ver com os meios de comunicação? Martino a tanto não dá esclarecimento, limitando-se a afirmar que os comunicólogos podem e devem criar uma abordagem autônoma a respeito daqueles meios e sua cultura.

Seus escritos comprometem-se relativamente mais na empreitada assim proposta porque, contrariamente aos de outros que lhe acompanham os passos, reivindicam abertamente para a epistemologia um poder fundacional em relação à cientificidade dos estudos em comunicação. Quem quer falar de ciência precisa entender, porém, que o que conta para sua instituição como tal não é mais, se é que algum dia assim ocorreu, este último tipo de discurso, mas as performances que a distinguiriam (LYOTARD, [1979] 1986).

0 primeiro e mais importante é o problema concreto e os métodos de análise que os materiais e a situações de trabalho nos proporcionam, visto que, se é possível começar a examinar a pesquisa a partir de um modelo (incluindo o comunicacional mais clássico), de outro lado jamais se sabe de antemão aonde ela chegará, se estiver comprometida com a aventura da descoberta. 0 conhecimento só é verdadeiramente novo quando não é predeterminado, ainda que formalmente, por um objeto estabelecido dogmaticamente

("o processo da comunicação" ou seu "aparato técnico") -antes cria seu caminho, elabora seu método, por mais que heuristicamente tenha de se valer de esquemas abstratos e genéricos.

Martino tem razão em protestar contra os doutrinadores dominantes na área, no sentido de que a interdisciplinaridade foi caracterização das atividades científicas da área proposta sem boa argumentação. Houve pouco ou nenhum esforço para, pelo menos, documentar a tese ou ilustrar o juízo. A presença de especialistas oriundos de vários ramos do saber na formação do campo, na construção de suas primeiras teorias, no subsequente oferecimento de seus métodos e na concretização de suas pesquisas etc., em geral, bastou para que se chegasse a tal conclusão.

A falta não significa, porém, que os pioneiros estejam errados; sinaliza a precariedade da reflexão epistemológica que se faz na área; mas, salvo prova em contrário, isso, por si só, não acarreta prejuízo à tese. 0 princípio em questão não foi, até agora, refutado do modo como, em sendo possível, se deve: isto é, com a apresentação do relato de pesquisa concreto e sua discussão epistemológica. A argumentação contra a insuficiência do discurso da interdisciplinaridade não pode dispensar a prova documental, sob pena de se bastar com a pregação abstrata, o doutrinarismo.

Aceita-se que haja uma distinção entre 0 "objeto de estudo de uma disciplina" e o "objeto 
de investigação referente a uma pesquisa"

(MARTINO, 2017 p. 44). Quem quer que queira abordar o primeiro, todavia, não pode desconhecer o que se passa na esfera do segundo. Vale distinguir entre filosofia geral da ciência e epistemologia (de cada ciência em especial). No segundo caso, a epistemologia pode, em sua variedade, ser vista como atividade "inerente às ciências sociais" (MARTINO, 2017, p. 39).

Avançar por aí, contudo, nada autoriza dizer que cabe à epistemologia estipular seus objetos de estudo, pouco importa se são empíricos ou teóricos (MARTINO, 2017, p. 46-48), nem muito menos arbitrar quem pode ou deve pesquisar mais adequadamente o que quer que seja. Que lhe toque esclarecer o objeto de uma atividade científica e sua história se admite, mas isso só se logra bem escapando do voluntarismo doutrinário e à prescrição normativa, se ela se mantiver atenta ao que de fato se faz na própria prática - o único plano em que a ciência importa apenas como ciência.

Enveredar por senda especulativa significa, em nosso ver, conferir à epistemologia uma tarefa doutrinaria (MARTINO, 2017, p. 118), o que no caso não surpreende, visto Martino não se interessar pelo que se faz no campo, mas apenas sobre o que a seu respeito se pensa e, em tese, esse campo deve admitir para se tornar ciência.

Todo o seu esforço se resume em polemizar com os doutrinadores da área; jamais examina a matéria mesma que lhes enseja o discurso, a única instância que, em tese, nos faria pôr os pés no terreno da atividade científica.

Em vez da análise do saber efetivamente existente no campo, o que se vê, por isso, é antes uma teorização sobre o que ele deveria ser, um teoricismo não isento de ressentimento gnosiológico para com as ciências estabelecidas, no qual se perde de vista a investigação e seus resultados para o conhecimento. Em vez de crítica potencialmente capaz de provocar reflexão na pesquisa, observa-se a epistemologia se esgotar em esforço para tratar um setor administrativo como disciplina científica, em tentativa de legitimar uma repartição acadêmica por meio de uma filosofia da ciência que, talvez, tenha hoje se tornado extemporânea (RÜDIGER, 2017a, p. 14-18; RÜDIGER, 2007) $)^{10}$.

\section{Conclusão}

$$
\begin{aligned}
& \text { Martino vê a fragmentação temática e a } \\
& \text { incoerência metodológica presentes no campo } \\
& \text { como problema, supondo que esse, no entanto, } \\
& \text { pode ser solucionado, mediante a reinterpelação } \\
& \text { da comunicação como disciplina possuidora de um }
\end{aligned}
$$


objeto de estudo bem delimitado (BOAVENTURA, VARÃo, 2016, p. 9). Argumenta que isso está ao seu alcance, à medida que, abandonando as referências alienígenas, a comunidade acadêmica do setor for percebendo e passando a aceitar que esse objeto é a "atualidade midiática", como bem observam em seu comentário Karin Boaventura e Rafiza Varão (p. 15).

A razão para 0 mal-estar do autor, para seu desgosto com a falta de disciplina da área, todavia, não somente parece extemporânea como carece de fundamentação à luz dos critérios que definiriam a atividade científica, se esta for julgada de acordo com os parâmetros de uma epistemologia que abriu mão das fantasias imperialistas e, agora, apresenta-se atenta, sobretudo, aos desenvolvimentos objetivos da produção do conhecimento (RÜDIGER, 2017a).

Para ele, "a sedução da posição interdisciplinar mantém-se às expensas do desenvolvimento da reflexão epistemológica" (MARTINO, 2017, p. 194). A possibilidade de que, embora pouco reflexiva e argumentada, esta posição, no entanto, se ampare na pesquisa efetivamente feita na área é descartada. 0 resultado é, em nosso juízo, um discurso abstrato, de pouco ou nenhum impacto no desenvolvimento da atividade científica que pode comparecer no campo. A epistemologia nos é apresentada como "reflexão sobre a teoria", em vez de estudo crítico e analítico da investigação efetivamente realizada.

Quem quer que, objetivamente, se dedique ao assunto concluirá que a pesquisa, enquanto processo de conhecimento empírico/experimental, é síntese de diverso, que inclui a teoria, mas remete a muito mais, ao englobar inúmeros outros fatores (STÖGNER, 2016) ${ }^{11}$. Isto é, precisa ser analisada caso a caso, desconstruída e comentada individualmente — se é, mesmo, para elaborarmos, como deseja 0 autor, uma ideia mais ou menos geral de qual é, de fato, a epistemologia dos estudos feitos na área de comunicação.

Pondo a tese de lado, verifica-se, por isso, que seus textos exaltam a epistemologia assimilando academicamente um fato do senso comum: a crescente presença dos meios de comunicação, para convertê-lo normativamente em referência da suposta singularidade científica de uma área do conhecimento. Transformam o fato político e administrativo que representou a criação da área acadêmica de comunicação, sem dúvida nenhuma ligado ao enorme impacto das tecnologias

11 Concordo com Martino (2010, p. 147-148) que, na atividade científica, "é inaceitável opor ou separar o empírico da teoria". Varia, no entanto, a primazia que atribuímos a um e outro aspecto. Para ele, "é o nexo com a teoria que caracteriza a pesquisa". Em meu ver, a relevância epistêmica da pesquisa é função de o que ensina a análise do caso especificamente em questão (experiência no sentido radical). Seguidor de Wright Mills (1961), também eu previno contra os prejuízos do empirismo e do teoricismo. Convém notar, porém, que isso não anula a possibilidade analítica de distinguir entre pesquisa e reflexão. Significa que, para fins de ajuizamento concreto, se altera a primazia de uma e outra, quando se passa do estudo de caso (empírico ou histórico) para a exposição genérica (teorética). 
portadoras do nome na sociedade, em carta de franquia para a postulação de sua autonomia epistemológica, sem, todavia, adentrar no exame concreto de suas atividades de investigação.

De acordo com Martino, é movimentando-se pela teoria (epistemologia) que a área (pesquisa) se consolidará como saber autônomo (ciência). Assombra-lhe as iniciativas, por isso, a figura do doutrinador todo-poderoso, derivada do rei-filósofo platônico, supostamente capaz de comandar o real por decreto. Fora das reuniões acadêmicas e juízos filosóficos, tudo isso, porém, nos parece vão. Devido ao cunho prescritivo e à falta de confrontamento crítico com 0 assunto mesmo - isto é, a atividade de investigação efetivamente desenvolvida no campo -, talvez sequer tenha muito alcance hermenêutico.

Apoia-se 0 autor na premissa de que houve um "embotamento da reflexão epistemológica" na área, para, assim, contrabandear a tese de que, se não é, ela pode e deve ser disciplina. A situação com que se confronta, todavia, pode ter mais consistência e solidez do que lhe parece. 0 consenso a respeito do caráter indisciplinado dos estudos feitos na área acadêmica de comunicação sempre careceu, é fato, da devida reflexão epistemológica. 0 fato, porém, não impediu 0 avanço e aceitação de seus trabalhos, que seguem se multiplicando aos milhares em eventos e publicações acadêmicas.

Que o referido consenso possa ser posto em questão não é de modo algum difícil de aceitar, considerando a variedade de gabarito que se encontra nesta produção virtualmente obscena. 0 problema surge quando, ignorando não os porta-vozes, mas a pesquisa realmente feita na área, desautoriza-se 0 que de fato define toda atividade científica: 0 trabalho de investigação efetivamente desenvolvido.

Salvo melhor juízo, a cientificidade não é algo que se instaure com base no decreto epistemológico. As exigências de cientificidade feitas à prática de pesquisa podem ajudar a criar um clima propício ao desenvolvimento de seu rigor. 0 principal, contudo, está no trabalho de investigação e de análise metódicas da experiência: é este trabalho que precisa ser tratado pela epistemologia, se esta não deseja assumir um cunho doutrinário.

Tivesse um repertório de realizações científicas singulares e autônomas para exibir, a comunicação, como área, poderia sem problema ensejar o desenvolvimento de seu próprio discurso epistemológico. Acontece, porém, que não é esse, até agora, o caso. Por isso, convém que se maneje com cuidado o emprego desse recurso filosófico, para não cairmos no cientificismo (na ideologia da ciência).

Pertence à epistemologia o relato sobre 0 estudo objetivo do que se oferece à experiência, na medida em que interessa a análise filosófica dos fundamentos teóricos e metodológicos da pesquisa. Pretender que ela, por si só, possa instaurar um discurso disciplinar tem seu atrativo 
ou poder de encanto em meio à área ainda muito nova no setor acadêmico. Em si mesmo, parecenos projeto de pouca ou nenhuma repercussão promissora no tocante ao avanço do conhecimento.

\section{Referências}

ADORNO, T.; HORKHEIMER, M. Dialética do

Esclarecimento. Rio de Janeiro: Zahar, 1985.

BOAVENTURA, K.; VARÃO, R. Uma bifurcação: Ronald Craig, Luiz Claudio Martino e a fundamentação do campo da comunicação. In Anais da Compós. Goiânia: Compós, 2016.

BRAGA, José Luiz. Análise performativa: cem casos de pesquisa empírica em comunicação. In BRAGA, J. L. et al. (orgs.), Pesquisa empírica em comunicação. São Paulo: Paulus, 2010.

FAY, Brian. Critical social science. Ithaca: Cornell University Press, 1987.

FEENBERG, Andrew. The philosophy of praxis. Londres: Verso, 2014.

FERRARA, Lucrécia. A comunicação: da epistemologia ao empírico. In Anais da Compós, Belém do Pará: Compós, 2014.

FRANÇA, Vera. 0 objeto e a pesquisa em comunicação. In MOURA, C.; LOPES, M. I. (orgas.), Pesquisa em Comunicação. Porto Alegre: Edipucrs, 2016.

FRANÇA, V.; SIMÕES, P. Curso básico de teoria da comunicação. Belo Horizonte: Autêntica, 2017.

HABERMAS, Jürgen. Teoria y práxis. Madri: Tecnos, 1987.

La lógica de las ciencias sociales. Madri: Tecnos, 1988.

HJARVARD, Stig. A Midiatização da cultura e da sociedade. São Leopoldo: Unisinos, 2014.
JACKS, Nilda (orga.). Meios e audiências. Porto Alegre: Sulina, 2008.

KLIMSTER, Richard. Praxis and method. Londres: Routledge, 1979.

KUHN, Thomas. A estrutura das revoluções científicas. São Paulo: Perspectiva, 1975.

LOPES, M. I. Pesquisa em comunicação. São Paulo: Loyola, 1990. (orga.) Epistemologia da Comunicação. São Paulo: Loyola, 2003. Reflexividade e relacionismo como questões epistemológicas na pesquisa empírica em comunicação. In BRAGA, J.; LOPES, M.I.; MARTINO, L. (orgs), Pesquisa empírica em comunicação. São Paulo: Paulus, 2010.

LUNDBY, Knut. (org.). Mediatization of communication. Berlim: Gruyther, 2014.

LYOTARD, Jean-François. 0 pós-moderno. Rio de Janeiro: José Olympio, 1986.

MARTINO, Luiz Claudio. Escritos sobre

Epistemologia da Comunicação. Porto Alegre: Sulina. 2017.

Panorama da pesquisa empírica em comunicação. In BRAGA, J.; LOPES, M.I.; (org.), Pesquisa empírica em comunicação. São Paulo: Paulus, 2010.

Teorias da comunicação: muitas ou poucas? Cotia: Ateliê, 2007.

Apontamentos epistemológicos sobre a fundação e fundamentação do campo da comunicação. In E-compós, Brasília, v. 1, p. 1-17, 2004.

As epistemologias contemporâneas e o lugar da Comunicação. In LOPES, M. I. (Orga.), Epistemologia da comunicação. São Paulo: Loyola, 2003.

Elementos para uma epistemologia da 
comunicação. In FAUSTO NETO, A.; PRADO, J.L.; PORTO, S.D. (orgs.), Campo da comunicação. João Pessoa: Editora Universitária, 2001.

MATTOS, M. A. et al. Metapesquisa em comunicação. Porto Alegre: Sulina, 2018.

MENDES DE BARROS, Laan. Comunicador e comunicólogo. In Communicare, São Paulo, v. 4, n.1, p. 9-14, 2004.

MERRIN, William. Media studies 2.0 Nova York: Routledge, 2014.

MILLS, Wright. La imaginación sociológica. México: FCE, 1961.

MOREIRA, Roberto. Teoria da comunicação.

Petrópolis: Vozes, 1979.

POLISTCHUK, I; RAMOS TRINTA, A. Teorias da comunicação. Rio de Janeiro: Elsevier, 2003.

RAYMOND, Pierre. L'histoire et les sciences. Paris: Maspero, 1978.

RÜDIGER, Francisco. Da epistemologia como projeto especulativo: a "ciência" da comunicação segundo José Luiz Braga. In Revista Eptic, Vitória, v. 19, n. 3, p. 7-22, 2017. Da filosofia da ciência à crise da epistemologia: contribuição à consciência reflexiva da área de comunicação. In Animus, Santa Maria, v. 16, n. 31, p. 1-22, 2017a.

Os estudos de mídia e a problemática epistemológica da teoria da midiatização: uma nova escolástica? Intexto, Porto Alegre, n. 34, p. 745-769, set./dez. 2015.

. Epistemologia "da" Comunicação: elementos para a crítica de uma fantasia acadêmica. In Famecos, Porto Alegre, v. 21, n. 2, p 395-417, 2014.

As Teorias da Comunicação. Rio de Janeiro:
. A comunicação no saber pós-moderno.

In FERREIRA, J. (org.), Cenários, teorias e

epistemologias da comunicação. Rio de Janeiro: e-papers, 2007.

\section{Ciência social crítica e pesquisa em}

comunicação. São Leopoldo: Unisinos, 2003.

SÁ, Adísia (orga.). Fundamentos científicos da comunicação. Petrópolis: Vozes, 1973.

STÖGNER, Karin. Against the reification of theory and praxis: critical theory and empirical social research. In LUDOVISI, S. (org.), Critical theory and the challenge of praxis. Nova York: Routlege, 2016. 


\begin{tabular}{|l|l|l|}
\hline $\begin{array}{l}\text { Unempowered Epistemological } \\
\text { Advocacy: The science of } \\
\text { Communication according } \\
\text { to Luiz Claudio Martino }\end{array}$ & $\begin{array}{l}\text { Abogacía epistemológica } \\
\text { desarmada: la ciencia de }\end{array}$ \\
\hline $\begin{array}{l}\text { Abstract } \\
\text { Luiz Claudio Martino has developed an essential } \\
\text { contribution to the genesis of the academic area } \\
\text { that has assumed the title of epistemology of } \\
\text { communication among us. This article sums up his } \\
\text { proposal and articulate a critical commentary about } \\
\text { it. It concludes that in spite of its seriousness and } \\
\text { high academic standarts its argumentation does } \\
\text { not sustain well its thesis in favor of the scientific } \\
\text { autonomy of the academic area of communication. } \\
\begin{array}{l}\text { Keywords } \\
\text { Luiz Claudio Martino. Epistemology of Communication. } \\
\text { Critique of Communicational Thinking. }\end{array}\end{array}$ & $\begin{array}{l}\text { Resumen } \\
\text { Luiz Claudio Martino ha desarrollado una } \\
\text { contribución esencial a la génesis del área académica } \\
\text { que, entre nosostros, ha asumido el nombre de } \\
\text { epistemología de la comunicación. Este artículo } \\
\text { resume la propuesta y teje un comentario crítico al } \\
\text { respecto. Concluye que, a pesar de su seriedad y alto } \\
\text { nivel académico, la argumentación por él presentada } \\
\text { no sostiene a bien su defensa de la autonomía } \\
\text { científica del área académica de la comunicación. } \\
\text { Palabras-clave } \\
\text { Luiz Claudio Martino; Epistemologia de la } \\
\text { Comunicação; Crítica del Pensamiento Comunicacional. }\end{array}$ \\
\hline
\end{tabular}




\section{Expediente}

A revista E-Compós é a publicação científica em formato eletrônico da Associação Nacional dos Programas de Pós-Graduação em Comunicação (Compós). Lançada em 2004, tem como principal finalidade difundir a produção acadêmica de pesquisadores da área de Comunicação, inseridos em instituições do Brasil e do exterior.

\section{E-COMPÓS I www.e-compos.org.br I E-ISSN 1808-2599}

Revista da Associação Nacional dos Programas de Pós-Graduação em Comunicação. Brasília, v.21, n.2, maio/ago. 2018. A identificação das edições, a partir de 2008, passa a ser volume anual com três números. Indexada por Latindex I www.latindex.unam.mx

\section{CONSELHO EDITORIAL}

Ada Cristina Machado Silveira, Universidade Federal de Santa Maria, Brasil Alda Cristina Silva da Costa, Universidade Federal do Pará, Brasil Alfredo Luiz Paes de Oliveira Suppia, Universidade Estadual de Campinas, Brasil Ana Regina Barros Rego Leal, Universidade Federal do Piauí, Brasil Ana Carolina Rocha Pessôa Temer, Universidade Federal de Goiás, Brasil André Luiz Martins Lemos, Universidade Federal da Bahia, Brasil Angela Cristina Salgueiro Marques, Universidade Federal de Minas Gerais, Brasil Ângela Freire Prysthon, Universidade Federal de Pernambuco, Brasil Anna Cristina Pertierra, Western Sidney University - Australia Antonio Carlos Hohlfeldt, Pontifícia Universidade Católica do Rio Grande do Sul, Brasil Arthur Ituassu, Pontifícia Universidade Católica do Rio de Janeiro, Brasil Bruno Campanella, Universidade Federal Fluminense, Brasil Bushra Rahman, University of the Punjab, Paquistão Cláudio Novaes Pinto Coelho, Faculdade Cásper Líbero, Brasil Cárlida Emerim, Universidade Federal de Santa Catarina, Brasil Carlos Del Valle Rojas, Universidad de La Frontera, Chile Carlos Eduardo Franciscato, Universidade Federal de Sergipe, Brasil Danilo Rothberg, Universidade Estadual Paulista, Brasil Denise Tavares da Silva, Universidade Federal Fluminense, Brasil Diógenes Lycarião, Universidade Federal do Ceará, Brasil Doris Martines Vizcarrondo, Universidad de Porto Rico, Porto Rico Eduardo Vicente, Universidade de São Paulo, Brasil Eliza Bachega Casadei, Escola Superior de Propaganda e Marketing - SP, Brasil Elvira Gomes dos Reis, Universidade do Cabo Verde, Cabo Verde Eneus Trindade, Universidade de São Paulo, Brasil Erick Felinto de Oliveira, Universidade do Estado do Rio de Janeiro, Brasil Erick Torrico, Universidad Andina Simón Bolívar, Bolívia Erly Vieira Júnior, Universidade Federal do Espírito Santo, Brasil Fabio La Rocca, Université Paul Valéry Montpellier III, França Fernando Firmino da Silva, Universidade Federal da Paraíba, Brasil Francisco de Assis, FIAM-FAAM Centro Universitário, Brasil Francisco Elinaldo Teixeira, Universidade Estadual de Campinas, Brasil Francisco Gilson R. Pôrto Jr., Universidade Federal do Tocantins, Brasil Francisco Sierra Caballero, Ciespal, Equador

Frederico de Mello Brandão Tavares, Universidade Federal de Ouro Preto, Brasil Gabriela Reinaldo, Universidade Federal do Ceará, Brasi Gérman Rey, Pontifícia Universidad Javeriana, Colômbia Gilson Vieira Monteiro, Universidade Federal do Amazonas, Brasil Gustavo Daudt Fischer, Universidade do Vale do Rio dos Sinos, Brasil Gustavo Hernández Díaz, Universidad Central de Venezuela, Venezuela Heidi Figueroa Sarriera, Universidad de Puerto Rico, Porto Rico Ignacio Aguaded, Universidad Huelva, Espanha

Inesita Soares de Araújo, FIOCRUZ, Brasil Itania Maria Mota Gomes, Universidade Federal da Bahia, Brasil Jiani Adriana Bonin, Universidade do Vale do Rio dos Sinos, Brasil João Carlos Correia, Universidade de Beira Interior, Portugal Jonathan Cohen, da University of Haifa, Israel José Afonso da Silva Junior, Universidade Federal de Pernambuco, Brasil José Luiz Aidar Prado, Pontifícia Universidade Católica de São Paulo, Brasil Josette Maria Monzani, Universidade Federal de São Carlos, Brasil Juçara Gorski Brittes, Universidade Federal de Ouro Preto, Brasil Julián Durazo Herrmann, Université du Québec à Montréal Juliana Freire Gutmann, Universidade Federal da Bahia, Brasil
Karla Covarrubias, Universidad de Colima, México Laura Loguercio Cánepa, Universidade Anhembi Morumbi, Brasil Leonel Azevedo de Aguiar, Pontifícia Universidade Católica do Rio de Janeiro, Brasi Letícia Cantarela Matheus, Universidade do Estado do Rio de Janeiro, Brasil Ling Chen, Hong Kong Baptist University Luciana Coutinho Souza, Universidade de Sorocaba, Brasil Maria Ataide Malcher, Universidade Federal do Pará, Brasil Maria Elena Hernández Ramírez, Universidad de Guadalajara, México Maria Elisabete Antonioli, Escola Superior de Propaganda e Marketing - SP, Brasil Maria das Graças Pinto Coelho, Universidade Federal do Rio Grande do Norte, Brasil Maria Teresa Quiroz, Universidad de Lima, Peru Marialva Carlos Barbosa, Universidade Federal do Rio de Janeiro, Brasil Marina Poggi, Universidad Nacional de Quilmes, Argentina Marcel Vieira Barreto Silva, Universidade Federal da Paraíba, Brasil Marcia Tondato, Escola Superior de Propaganda e Marketing, Brasil Marli Santos, Universidade Metodista de São Paulo, Brasil Márcio Souza Gonçalves, Universidade do Estado do Rio de Janeiro, Brasil Mateus Yuri Passos, Universidade Metodista de São Paulo, Brasil Mauricio Mario Monteiro, Universidade Anhembi Morumbi, Brasil Mayka Castellano, Universidade Federal Fluminense, Brasil Mirna Varela, Universidad de Buenos Aires, Argentina Mozahir Salomão Bruck, Pontifícia Universidade Católica de Minas Gerais, Brasil Neyla Pardo, Universidad Nacional de Colombia, Colombia Nísia Martins Rosario, Universidade Federal do Rio Grande do Sul, Brasil Olga Guedes Bailey, Nottingham Trent University, Inglaterra Paolo Demuru, Universidade Paulista, Brasil Paolo Peverini, L.O.U.I.S.S de Roma, Itália

Paško Bilić, Institute for Development and International Relations, Croácia Paula Melani Rocha, Universidade Estadual de Ponta Grossa, Brasil Potiguara Mendes Silveira Jr, Universidade Federal de Juiz de Fora, Brasil Priscila Ferreira Perazzo, Universidade Municipal de São Caetano do Sul, Brasil Rafael Cardoso Sampaio, Universidade Federal do Paraná, Brasil Rafael Tassi Teixeira, Universidade Tuiuti do Paraná, Brasil Regiane Lucas Garcês, Universidade Federal de Minas Gerais, Brasil Regiane Regina Ribeiro, Universidade Federal do Paraná, Brasil Renata Pitombo Cidreira, Universidade Federal do Recôncavo da Bahia, Brasil Renato Essenfelder, Escola Superior de Propaganda e Marketing, Brasil Roberto Elísio dos Santos, Universidade Municipal de São Caetano do Sul, Brasil Robson Borges Dias, Universidade Católica de Brasília (UCB), Brasil Rodolfo Rorato Londero, Universidade Estadual de Londrina, Brasil Rosario Sánchez Vilela, Universidad Católica del Uruguay, Uruguai Roseli Figaro, Universidade de São Paulo, Brasil

Saima Saeed, Jamia Millia Islamia, India Sara Brandelero, Leyden University, Holanda

Simone Maria Andrade Pereira de Sá, Universidade Federal Fluminense, Brasil Sônia Caldas Pessoa, Universidade Federal de Minas Gerais, Brasil Sun Sun Lim, Singapore University of Technology and Design, Singapura Tatiana Oliveira Siciliano, Pontifícia Universidade Católica do Rio de Janeiro, Brasil Thaïs de Mendonça Jorge, Universidade de Brasília, Brasil Valquiria Michela John, Universidade Federal do Paraná, Brasil Vicki Mayer, Tulane University, Estados Unidos Yamile Haber Guerra, Universidad de Oriente, Cuba 


\section{CONSELHO CIENTÍFICO}

Cristiane Freitas Gutfreind, Pontifícia Universidade Católica do Rio Grande do Sul, Brasil I Eduardo Antônio de Jesus, Universidade Federal de Minhas Gerais, Brasil | Eduardo Morettin, Universidade de São Paulo, Brasil I Irene de Araújo Machado, Universidade de São Paulo, Brasil | Miriam de Souza Rossini, Universidade Federal do Rio Grande do Sul, Brasil

\section{COMISSÃO EDITORIAL}

Igor Pinto Sacramento, Universidade Federal do Rio de Janeiro, Brasil । Kelly Cristina de Souza Prudencio, Universidade Federal do Paraná, Brasil । Osmar Gonçalves dos Reis Filho, Universidade Federal do Ceará, Brasil | Rafael Grohmann, Faculdade Cásper Líbero, Brasil | Thaiane Moreira de Oliveira, Universidade Federal Fluminense, Brasil (editores associados)

\section{CONSULTORES AD HOC}

Alessandro Constantino Gamo, Universidade Federal de São Carlos (UFSCAR) | Amanda Mauricio Pereira Leite, Universidade Federal do Tocantins (UFT) | Amílcar Almeida Bezerra, Universidade Federal de Pernambuco (UFPE) I Ana Carolina Damboriarena Escosteguy, Universidade Federal de Santa Maria (UFSM) I Ana Luiza Coiro Moraes, Faculdade Cásper Líbero | Antonio Pacca Fatorelli, Universidade Federal do Rio de Janeiro (UFRJ) | Ariane Diniz Holzbach, Universidade Federal Fluminense (UFF) I Benjamin Picado, Universidade Federal Fluminense (UFF) I César Augusto Baio dos Santos, Universidade Federal do Ceará (UFC) I César Geraldo Guimarães, Universidade Federal de MInas Gerais (UFMG) I César Ricardo Siqueira Bolaño, Universidade de Brasília (UNB) I Ciro Marcondes Filho, Universidade de São Paulo (USP) I Felipe Simão Pontes, Universidade Estadual de Ponta Grossa I Felipe Trotta, Universidade Federal Fluminense (UFF) I Gislene da Silva, Universidade Federal de Santa Catarina (UFSC) I Kati Caetano, Universidade Tuiuti do Paraná I Laan Mendes de Barros, Universidade Estadual Paulista Júlio de Mesquita Filho I Lucia Leão, Pontifícia Universidade Católica de São Paulo (PUC-SP) I Jairo Getulio Ferreira, Universidade do Vale do Rio dos Sinos (UNISINOS) | Juliana Doretto, FIAM-FAAM | Juliano Maurício de Carvalho, Universidade Estadual Paulistaa Júlio de Mesquita Filho | Lilian Cristina Monteiro França, Universidade Federal de Sergipe I Liziane Soares Guazina, Universidade de Brasília (UNB) I Luís Mauro Sá Martino, Faculdade Cásper Líbero | Luiz Peres Neto, Escola Superior de Propaganda e Marketing (ESPM) I Herom Vargas, Universidade Metodista de São Paulo I Inês Silvia Vitorino Sampaio, Universidade Federal do Ceará (UFC) I Maria Helena Weber, Universidade Federal do Rio Grande do Sul (UFRGS) I Mariana Baltar, Universidade Federal Fluminense (UFF) I Maurício de Bragança, Universidade Federal Fluminense (UFF) I Mauro de Souza Ventura- Universidade Estadual Paulista Júlio de Mesquita Filho I Muniz Sodre de Araujo Cabral, Universidade Federal do Rio de Janeiro (UFRJ) I Nuno Manna, Universidade Federal da Bahia (UFBA) I Rosana de Lima Soares, Universidade de São Paulo (USP) I Sandra Maria Lúcia Pereira Gonçalves, Universidade Federal do Rio Grande do Sul (UFRGS) I Sérgio Luiz Gadini, Universidade Estadual de Ponta Grossa I Talitha Gomes Ferraz, Escola Superior de Propaganda e Marketing (ESPM) I Victa de Carvalho Pereira da Silva, Universidade Federal do Rio de Janeiro (UFRJ)

\section{EQUIPE TÉCNICA}

ASSISTENTES EDITORIAL Melina Santos | REVISÃO DE TEXTOS Fátima Áli | EDITORAÇ̃̃o ELETRÔNICA Roka Estúdio

COMPÓS I www.compos.org.br

Associação Nacional dos Programas de Pós-Graduação em Comunicação

Presidente

Marco Roxo

Programa de Pós-Graduação em Comunicação - UFF marcos-roxo@uol.com.br

Vice-Presidente

Isaltina Gomes

Programa de Pós-Graduação em Comunicação - UFPE

isaltina@gmail.com

Secretária-Geral

Gisela Castro

Programa de Pós-Graduação em Comunicação

e Práticas de Consumo - ESPM

castro.gisela@gmail.com

CONTATO I revistaecompos@gmail.com 